\title{
Children with juvenile chronic arthritis: their beliefs about their illness and therapy
}

\author{
J. GERALD BEALES, P. J. LENNOX HOLT, JOHN H. KEEN, AND \\ VALERIE P. MELLOR
}

From the Department of Rheumatology, University of Manchester Medical School, Stop ford Building, Oxford Road, Manchester; Manchester Royal Infirmary, Oxford Road, Manchester; and Booth Hall Children's Hospital, Blackley, Manchester

SUMMARY Seventy-five patients aged 7 to 17 with juvenile chronic arthritis were interviewed to identify their beliefs about the physical nature of their illness and the relevance and modes of action of their clinical treatment. Children in the 7-11 age group were found to perceive their arthritis largely in terms of its immediate manifestations, to have little conception of internal pathology, and to be less aware of the value of their medical therapy. Children in the 12-17 age group showed a greater tendency to recognise arthritis as a condition of internal pathology, to experience distressing fantasies about the internal appearance of their affected joints, and to appreciate the purpose of their therapy.

Although a child's beliefs about the physical nature of his illness may greatly influence the amount of emotional distress he experiences and even his willingness to comply with therapy, there has been hardly any systematic investigation of how patients with juvenile chronic arthritis (JCA) of different ages perceive their condition.

It is evident, however, that children's understanding of disease and medical therapy is more determined by age ${ }^{1-3}$ than by such factors as $\mathrm{sex}^{14}$ socioeconomic class, ${ }^{1}$ or maternal influence,${ }^{15}$ and a few recent studies ${ }^{4-8}$ have suggested that children's beliefs about illness proceed through a series of discrete stages broadly in accordance with the theoretical framework of intellectual development set out by Piaget and Innhelder. ${ }^{9}$

According to Piaget and Innhelder, in the 'preoperational' stage of cognitive development (from approximately 2 through to 7 years of age) the child is incapable of reasoning beyond his own immediate experience and beyond appearances. Things are as they seem to be rather than as they logically must be. Consequently a child will report that a tall, thin glass contains more liquid than a short, wide one because the level of the liquid is higher, even if he has seen equal amounts poured into them. Words have only a single meaning, and are taken literally. In a study of

Accepted for publication 22 July 1982.

Correspondence to Dr J. G. Beales, Department of Rheumatology, University of Manchester, Stopford Building, Oxford Road, Manchester M13 9PT. healthy children Perrin and Gerrity ${ }^{4}$ found that youngsters in this age group tended to identify illness solely according to its directly experienced manifestations: 'being ill' was having to stay in bed. In another study involving healthy children Bibace and Walsh ${ }^{8}$ reported that the 'preoperational' child does not spontaneously conceptualise the internal structure of his body; instead, the body is perceived essentially in terms of its visible surface.

At around the age of 7 years Piaget and Innhelder state that the child progresses into a qualitatively different style of thinking and this "concrete operational' stage continues up to the age of approximately 11 . The youngster can now use elementary logic and is capable of developing simple, causal explanations to account for illness and recovery. ${ }^{4}$ Thought, however, remains substantially limited to the child's own concrete experience of objects and events. It is only in the stage of 'formal operations' (which begins at around the age of 12) that the child becomes capable of abstract thought, of conceptualising unseen objects and phenomena, and of perceiving illness in physiological terms. ${ }^{4} 78$

An investigation of beliefs about JCA and its treatment was conducted as part of a wider long-term psychological study of 75 JCA patients. At the time of this investigation the children were aged between 7 and 17 and it was expected that children in the 7-11 and 12-17 age groups would perceive their arthritis and therapy in qualitatively different ways. It was expected that the $12-17 \mathrm{~s}$ would recognise arthritis as 
a condition of internal physical pathology, that they would be concerned about and distressed by events which they believed to be taking place beneath the skin surface, and that they would appreciate the relevance and value of clinical therapy. The 7-11s, on the other hand, were expected to reveal a preoccupation with the immediate manifestations of their arthritis, to have little concern with and conception of internal pathology, and to be less aware of the relevance and mode of action of the treatment they were undergoing.

\section{Patients and methods}

The 75 patients in the sample were initially selected as consecutive attenders at juvenile rheumatology clinics held at Booth Hall Children's Hospital and St Mary's Hospital, Manchester. Almost two-thirds of the sample (48) were girls, and the patients varied considerably in terms of the duration and severity of their disease. Thirty-nine children were aged 7 to 11 , and 36 were aged 12 to 17 . Prior to this investigation all these children had been interviewed by J.G.B. (a social psychologist) on several occasions in order to obtain data on their pain experience and the implications of their disease for activities and ambitions. These previous interviews had been conducted in an informal manner in the child's own home, and consequently a useful rapport had been established between the interviewer and each patient in the sample. For this reason the children proved willing to disclose fears and fantasies about the physical nature of their arthritis which they were sometimes unwilling to admit to other adults for fear of ridicule. The interviews dealing with beliefs about the arthritis and its treatment were similarly conducted by J.G.B. in the child's home and in as informal a manner as possible.

Firstly, the child was asked precisely what he imagined his arthritis to be-how it affected his body and how it made his body different from that of a child who did not have the disease. The patient was encouraged to respond fully, but care was taken to avoid prompting the child to respond in particular terms. The responses were later divided by the interviewer into the following categories: (i) subjective feeling ('it makes me feel ill', 'it makes my fingers ache'); (ii) surface appearance ('it makes my knee look red and swollen'); (iii) motor ability ('I can't move my neck properly', 'it stops my fingers bending'); (iv) internal pathology ('it damages my bones', 'it fills my joints with blood').

The child was then offered paper and a box of large coloured wax crayons and asked to draw what he imagined his affected joints looked like 'inside'. When he had completed the drawing, he was asked to describe it and explain his choice of colours. In addi- tion he was asked to what extent thinking of his joints being as he had drawn them made him feel 'upset', 'sad', 'frightened', and 'worried'-indicating the extent of his distress on visual analogue scales. These scales were simply $100 \mathrm{~mm}$ lines, without intermediate divisions, and with extremes being described to the child as 'it doesn't make me (upset) at all' and 'it makes me as (upset) as I can imagine being'.

Finally the child was asked about the therapy he was receiving at present and (where this had changed) had received in the recent past. He was asked to describe each particular therapy (medicine, injections, splinting, etc.) and to explain what he imagined its purpose was-what precise improvement in the condition it was intended to achieve and by what means it produced its effect. He was also encouraged to report any thoughts he might have that therapy did not 'make sense' or was actually harmful. At the close of the interview a fixed-choice questionnaire concerning beliefs about the value of treatments (Table 3) was presented, each question being read to the child and the selected responses recorded by the interviewer.

Statistical analysis was by the chi-square and Fisher's exact tests.

\section{Results}

BELIEFS ABOUT PHYSICAL NATURE OF THE DISEASE

A broad difference was discerned between the beliefs and concepts of children aged between 7 and 11 years and those aged 12-17 years. A large majority of children in the 7-11 age group perceived the arthritis essentially in terms of its immediate concrete manifestations. When asked what arthritis was and how it affected their body, they replied that it made their knees ache or their fingers sore, that it made their elbows stiff or prevented their arms moving properly, that it made their ankles appear swollen or their legs look thin; for the great majority of the 7-11s these signs and symptoms of the disease were the disease itself. Only 5 children at the older end of this age group (10 and 11 years of age) perceived the subjective feelings, surface appearance, and restricted motor capacity as consequences of some internal pathology (Table 1). In the accounts of internal pathology provided by these 5 patients bones and blood figured prominently. They had some concept

Table 1 Descriptions of the physical nature of JCA

\begin{tabular}{lrll}
\hline JCA described as: & $7-11$ & $12-17$ & $p$ \\
\hline Subjective feeling & $34(87 \%)$ & $31(86 \%)$ & NS \\
Surface appearance & $23(59 \%)$ & $18(50 \%)$ & NS \\
Motor incapacity & $26(67 \%)$ & $24(67 \%)$ & NS \\
Internal pathology & $5(13 \%)$ & $23(64 \%)$ & $<0.001$ \\
\hline
\end{tabular}


of the body skeleton and knew that blood lay beneath the skin, although none was aware that blood actually circulated and that the heart played any part in this. Their images of what was taking place beneath the body surface were vague and undetailed, being based on information provided by parents and doctors ('there is something wrong with my blood'), or on reasoning from personal experience (as with the girl who deduced that, since she could not move her leg properly, something must be 'gluing' her bones together).

In contrast, approximately two-thirds of the $12-17 \mathrm{~s}$ perceived arthritis as a state of internal pathology and recognised the signs and symptoms which they were directly aware of as consequences and manifestations of damage existing out of sight, beneath the body surface. The majority of these children identified 'being ill' as an unseen process which involved body parts known only indirectly rather than purely as a state of conscious awareness and of visible anatomy. Bones and blood again figured prominently in the image of internal damage, with other tissues being scarcely mentioned. Even the oldest children, with long-standing disease, were unable to give a substantially accurate and detailed description of the physiology of arthritis. Any medical information which children in this age group had acquired tended to have been oversimplified and exaggerated by the child, so that the pathology which was imagined was frequently of a more extreme nature than was in fact the case. Images included gross swelling or splintering of bone and extensive haemorrhaging into and around the joint. The majority of $12-17 \mathrm{~s}$ appeared to assume that quite severe damage must be occurring beneath the skin surface in view of the severity of the symptoms and limitation of motor activity they experienced. There was no appreciation that less dramatic physiological events could give rise to significant levels of pain and physical incapacity.

Of those children in the older age group who did not perceive arthritis as a state of internal pathology all but one were aged 12 or 13 years, the exception being a 14-year-old girl whose slow intellectual development had led her to be placed in the remedial class of a normal secondary school.

FANTASIES ABOUT INTERNAL APPEARANCE ÓF AFFECTED JOINTS

When asked to draw what they imagined their affected joints looked like 'inside', all the children readily began the task, suggesting that the image they reproduced on paper was already 'in mind' and was not having to be newly created on this occasion. However, only a small minority (8) of the 7-11s actually drew internal structures and events. Most frequently an external view of a limb was shown, with the relevant joint depicted as red and swollen. Of those children who conceptualised events beneath the skin surface, 4 drew 'veins' and bones which had no obvious pathological features, nor were the children able to point out anything abnormal in the blood vessels and bones they had drawn. They simply reported that they believed something was wrong with them, but they did not know what. An 11-yearold girl used a brown crayon to show the bones of her arms and legs in the belief that 'they had gone a funny colour'. A 10-year-old girl drew her knee full of yellow substance which she likened to 'cold mashed potato' and which she believed was responsible for the visible swelling in addition to preventing her bones 'being able to move properly'. Finally an 11year-old girl drew a thin green line between the bones in her leg, which represented an unspecified substance 'gluing' the bones together.

All but 6 of the 12-17s portrayed the 'inside' of their affected joints when asked to do so as opposed to depicting surface features, and the majority of children in this age group drew quite obvious damage to bones and blood vessels. Large areas were often drawn in red to show extensive internal haemorrhaging, perhaps comparable in the child's mind to the quantity of blood which is seen to flow when the skin surface is significantly damaged. Although most of the older children simply outlined bones in black so that they would stand out as white objects on white paper, 9 children coloured their bones entirely in black. Four of them expressed the belief that the bones in the affected limbs really had become that colour, the remainder choosing black merely to represent serious pathology. For example, a 17-year-old girl explained that she had coloured the bones of her hand black simply because 'black is a horrible colour'.

Many of the 12-17s expressed distaste at their drawings immediately they had completed them. When asked to rate the extent to which imagining their joints as they had drawn them made them feel 'upset', 'sad', 'frightened', and 'worried', the older children gave significantly higher visual analogue scale scores than the 7-11s on each item (Table 2).

Table 2 Emotional distress produced by images of internal joint pathology

\begin{tabular}{lllr}
\hline $\begin{array}{l}\text { Mean visual analogue } \\
\text { scale scores* }\end{array}$ & $7-11$ & $12-17$ & $p$ \\
\hline Upset & 28 & 58 & $<0 \cdot 001$ \\
Worried & 30 & 60 & $<0 \cdot 001$ \\
Frightened & 20 & 35 & $0 \cdot 004$ \\
Sad & 28 & 47 & $0 \cdot 001$ \\
\hline
\end{tabular}

*Out of $100 \mathrm{~mm}$. 
Only 3 of the $12-17 \mathrm{~s}$ scored zero on all four items, in contrast to 9 of the 7-11s. None of those in the older age group indicated actual amusement at the imagined state of their joints, as did the 10-year-old girl who believed her knee to contain something resembling mashed potato.

\section{BELIEFS ABOUT ROLE OF THERAPY}

The 7-11s largely judged the relevance and likely effectiveness of therapy according to its directly recognisable effect on what they perceived the disease to be-i.e., unpleasant feelings, restricted motor ability, and abnormal surface appearance. Few appeared to think in terms of effect on internal pathology or to appreciate that treatments which themselves gave rise to immediate unpleasant feelings could have beneficial long-term consequences. Consequently (Table 3) 'nice-tasting medicine' was generally agreed to be 'good for you', simply because it did taste nice-it produced a pleasant feeling to counter the pain and discomfort of the disease. 'Nasty-tasting medicine' was felt, by a slight majority, to do more harm than good because it made them 'feel worse'-it added to the total of distressing sensations which were being experienced. Similarly, a sizeable minority of the 6-11s saw no value in taking tablets, which had no agreeable taste and might be difficult to swallow. When asked what happened to tablets after they had been swallowed, all the children in this age group indicated that they terminated their journey in the 'stomach' and could see no means by which they might travel to, and have an effect on, their joints. Nor could any of the 7-11s imagine the means by which injections might relieve pain in affected joints, improve their mobility, and restore a more normal surface appearance. Instead injections were more frequently seen to constitute physical assault upon the body, adding to the sum total of discomfort.

Younger children tended to assume that recovery of a damaged limb required that the affected part be rested and left undisturbed. Moving the limb was associated with increasing pain and aggravation of the condition. Therefore, although a majority of the 7-11s approved of physiotherapy conducted inside hospital, since it was presented as an enjoyable game, a significant minority believed that physiotherapy was making their arthritis worse. A similar division of opinion existed with regard to the wearing of splints. More than half of the younger children approved of splints in the belief that they helped to rest and protect affected body parts, but a sizeable minority perceived splints as making the condition worse by virtue of their further restricting mobility.

Although many 7-11s were apparently prepared to take on trust that having blood taken was necessary to their effective treatment, none had any conception of why it was necessary, and a slight majority again saw the puncturing of the skin predominantly as an assault upon the body and an aggravation of their physical distress.

Children in the 12-17 age group, however, generally had an appreciation of the fact that treatment which was immediately unpleasant could have a longer-term benefit upon their internal pathology. There was in fact a real belief that treatment was more likely to be effective if it was unpleasant. Consequently $17 \%$ of the $12-17 \mathrm{~s}$ indicated that 'nicetasting' medicine was actually to be disapproved of because it was concerned with providing immediate pleasure, instead of being essentially concerned with the real task of dealing with the internal condition. The majority of children in this age group accepted

Table 3 Beliefs about the value of treatments

\begin{tabular}{|c|c|c|c|c|c|}
\hline \multirow[t]{3}{*}{ If you have arthritis: } & \multicolumn{4}{|c|}{ Is more likely to: } & \multirow[t]{3}{*}{$p$} \\
\hline & \multicolumn{2}{|c|}{ make you better } & \multicolumn{2}{|c|}{ make you worse } & \\
\hline & $7-11$ & $12-17$ & $7-11$ & $12-17$ & \\
\hline \multirow[t]{3}{*}{$\begin{array}{l}\text { Taking nice-tasting medicine } \\
\text { Taking nasty-tasting medicine } \\
\text { Swallowing tablets } \\
\text { Having injections } \\
\text { Doing exercises } \\
\text { Wearing splints }\end{array}$} & $\begin{array}{l}39(100 \%) \\
19(49 \%) \\
23(59 \%) \\
11(28 \%) \\
24(62 \%) \\
22(56 \%)\end{array}$ & $\begin{array}{l}30(83 \%) \\
31(86 \%) \\
28(78 \%) \\
20(56 \%) \\
29(81 \%) \\
24(67 \%)\end{array}$ & $\begin{array}{l}0(0 \%) \\
20(51 \%) \\
16(41 \%) \\
28(72 \%) \\
15(38 \%) \\
17(44 \%)\end{array}$ & $\begin{array}{r}6(17 \%) \\
5(14 \%) \\
8(22 \%) \\
16(44 \%) \\
7(19 \%) \\
12(33 \%)\end{array}$ & $\begin{array}{l}0.024 \\
0.002 \\
\text { NS } \\
0.028 \\
\text { NS } \\
\text { NS }\end{array}$ \\
\hline & \multicolumn{2}{|l|}{ Yes } & \multicolumn{2}{|l|}{ No } & $p$ \\
\hline & $7-11$ & $12-17$ & $7-11$ & $12-17$ & \\
\hline $\begin{array}{l}\text { Having blood taken helps the } \\
\text { doctor to make you better }\end{array}$ & $19(49 \%)$ & $29(81 \%)$ & $20(51 \%)$ & $7(19 \%)$ & 0.009 \\
\hline
\end{tabular}


that some physical connection existed in the body whereby drugs swallowed or injected could reach the affected joints, although only a few at the older end of the group had an accurate ieda of what that connection might be.

\section{Discussion}

There may be some tendency among parents and clinicians to assume that it is kinder to keep a child with JCA largely uninformed about his condition. It may be felt that any discussion or description of the physical nature of the disease will only cause the child additional worry and distress, and this assumption can be confirmed by the child who indicates a preference for being ' $k e p t$ in the dark'. Younger children particularly may seek to cope with the psychological impact of their arthritis by denying its existence-by 'putting it out of mind' and seeking to avoid any discussion of it (Beales J. G., Holt P. J. L., Keen J. H., Mellor V. P., in preparation). In the short term, compelling these children to acknowledge their disease by providing them with a description of it can therefore cause them emotional distress, but any such consequence has to be weighed against the need to motivate the patient to comply with therapy. It is evident that their failure to conceptualise internal pathology and to create fantasies about the state of their joints caused many of the 7-11-year-old children to lack appreciation of the relevance of much of the treatment they were undergoing. Frequently this led to quite considerable conflict between patient and parents over the taking of prescribed drugs and the regular and conscientious performing of recommended exercises at home. Parents who were anxiously striving to ensure that the child followed 'doctor's orders' were themselves caused distress as a result of their having to punish or threaten the child 'for his own good'. Many parents wished to develop an especially close bond with their sick child, and resented the fact that their role as 'medicine givers' alienated their offspring from them. In a very few cases parents actually allowed themselves to be convinced by the child that some aspect of therapy was harmful rather than helpful. They ceased to enforce compliance with that part of the treatment and collaborated with the child in lying to the doctor about the extent to which medical advice was being followed. Appreciation of the relevance of their therapy was generally greater among the $12-17 \mathrm{~s}$, and inadequacies in their understanding of the clinical nature of arthritis primarily manifested themselves in the development of exaggerated and distressing beliefs and fantasies about internal pathology. When older children said that they would not welcome a clear explanation of the disease from the doctor, this was usually because they feared that the doctor would show their fantasies to be understatements of the truth.

The study also indicates that not only do 7-11s and $12-17 \mathrm{~s}$ require explanations of their arthritis for different reasons, they also require qualitatively different types of explanation. As other authors have indicated, ${ }^{78}$ children in the $12-17$ age group are usually capable of comprehending a simplified, 'textbook' style description of their condition phrased in abstract causal terms. Because 7-11-year-old children generally find difficulty in conceptualising abstract, unseen events and objects, patients in this age group would seem to require descriptions of the disease which make use of specific analogies drawn from their immediate experience. ${ }^{7}$ Much of anatomy and physiology can be likened to objects and processes which the child in this age group is familiar with: blood vessels being likened to pipelines and nerves to electric wiring, for example. Disease activity can often be described in military terms, which is sure to appeal to the boys at least, it being suggested, perhaps, that in the case of JCA the body's own defending forces have been less than competent at identifying the enemy and have turned on their own side by mistake.

Yet although a significant difference was found between the 2 age groups studied there was an appreciable overlap, so that it cannot be assumed that any 12-year-old patient can cope with a 'textbook' description, or that any 10-year-old requires the use of analogies. In addition it is likely that some 7- and 8-year-old patients encountered in clinical practice will still be at the previous 'preoperational' stage, and use of analogies with such children might have positively harmful consequences. Because a child at this stage interprets things literally, any reference to nerves as electrical wiring, for example, might in his case generate fears of lethal electric shock, if the parents have repeatedly warned him of the dangers of playing with plugs and sockets. ${ }^{7}$ The unfortunate results of a 'preoperational' child interpreting words literally were in fact graphically portrayed by a 5 -year-old JCA patient interviewed by J.G.B. in connection with a separate study. This young girl confessed that when she had heard the doctor describe her knee as 'inflamed', she had believed this to mean that, beneath the skin surface, her knee was actually 'in flames' and had subsequently been afraid that the fire would burn her leg completely away.

Further complication is introduced by the fact that Piaget's work has shown that a child may not be at the same stage of intellectual development in all areas of cognitive activity, and a child operating at the "concrete operational' stage of development so far as other aspects of intellectual functioning are con- 
cerned might conceivably regress to the 'preoperational' level of thought as regards all matters specifically relating to his illness.

If clinicians are to be able to tackle the problem of explaining JCA to their young patients with any degree of confidence, simple and reliable means of identifying the child's level of cognitive development in relation to the disease specifically must be found. For this reason, the authors are currently engaged in further work aimed at establishing such means, and at testing the effectiveness of different verbal, written, and pictorial methods of describing juvenile chronic arthritis to young patients of different ages.

This research was entirely supported by a grant from the Nuffield Foundation.

\section{References}

1 Campbell J D. Illness is a point of view: the development of children's concepts of illness. Child Dev 1975; 46: 92-100.
2 Steward M, Regalbuto G. Do doctors know what children know? Am J Orthopsychiatry 1975; 45: 146-9.

3 Neuhauser C, Hines P, Steward M. Children's concepts of healing: cognitive development and locus of control factor. $\mathrm{Am} \mathrm{J}$ Orthopsychiatry 1978; 48: 335-41.

4 Perrin E C, Gerrity P S. There's a demon in your belly: children's understanding of illness. Pediatrics 1981; 67: 841-9.

5 Mechanic D. The influence of mothers on children's health attitudes and behaviour. Pediatrics 1964; 33: 444-53.

6 Simeonsson R J, Buckley L, Monson L. Conceptions of illness causality in hospitalized children. J Pediatric Psychol 1979; 4: 77-84.

7 Whitt J K, Dykstra W, Taylor C A. Children's conceptions of illness and cognitive development: implications for pediatric practitioners. Clin Pediatr 1979; 18: 327-39.

8 Bibace R, Walsh M E. Development of children's concepts of illness. Pediatrics 1980; 66: 912-7.

9 Piaget J. Innhelder B. The psychology of the child. New York: Basic Books, 1969.

\section{Book review}

Clinical Orthopaedic Examination. 2nd Edn. By Ronald McRae. Pp. 231. £8.25. Churchill Livingstone: Edinburgh. 1983.

Medical orthopaedics covers a wide range of conditions that may be referred to the orthopaedic surgeon or rheumatologist depending on local conditions, in particular clinical pressures and consultant interest. The inadequacy of undergraduate teaching in both subjects means that systematic examination methods may not have been learnt and understood, and hence the application of standard tests and the interpretation of clinical findings may be poor.

This book, illustrated with some 900 line drawings and radiographs, will provide an excellent basic text for the unit house officer (and a useful reminder for the consultant). The initial impression is of a somewhat frightening catalogue of tests and signs, but taken in stages it is found to be systematic and comprehensive, emphasising the anatomical basis with the conditions described in in a brief commentary and illustrated by radiographs and drawings. The book concludes with a 68 question and answer radiographic quiz.

The rheumatologist might reasonably suggest that the inclusion of many of his specific questions and physical signs such as proximal interphalangeal joint circumference and measurement indices such as pain scales and articular indices would have added considerably to the value of the book without significantly increasing the number of pages. Further, the problems of interpretation of some tests and the potential inaccuracies of tape measurement are ignored. These are minor criticisms. This is an excellent book for the ward or clinic shelf; I recommend you buy it.

ALASTAIR G. MOWAT 